\title{
FRP積層板の弾性率と強度の解析
}

\author{
名古屋工業大学高分子工学科 高橋清久・木村昌樹・原川和久 \\ 工業技術院製品科学研究所伴 菊夫 \\ 東京工業大学有機材料工学科 酒井哲也
}

\section{ANALYTICAL PROCEDURE TO PREDICT THE ELASTIC MODULI AND BREAKING STRENGTHS OF FRP LAMINATES}

\author{
By Kiyohisa Takahashi ${ }^{* 1}$, Masaki Kimura ${ }^{* 1}$, Kazuhisa Harakawa ${ }^{* 1}$, \\ Kikuo Ban ${ }^{* 2}$ and Tetsuya Sakai ${ }^{* 3}$ \\ *1 (Department of Polymer Engineering, Nagoya Institute of Technology, \\ Gokiso-cho, Showa-ku, Nagoya 466, Japan) \\ *2 (Industrial Products Research Institute, 1-1-4, Yatabe-machi Higashi, \\ Tsukuba-gun, Ibaraki 305, Japan) \\ *3 (Tokyo Institute of Technology, O-okayama, Meguro-ku, Tokyo 152, \\ Japan)
}

An analytical procedure to predict the effective stress-strain relations of FRP laminates is developed, based on the stress analysis of unidirectional FRP reported in a previous paper" ${ }^{1)}$. The laminate is considered to consist of $N$ plies of unidirectional FRP. Each ply is composed of continuous, transversely isotropic fibers and an isotropic matrix. The stress components in the thickness direction of the laminate are assumed to vanish. The quadratic failure criterion proposed by Tsai and $\left.\mathrm{Wu}^{2}\right)$ is applied to each ply, and the external stress $\sigma_{B}^{i}$ at which $i$-th ply fails is estimated $(i=1 \sim N)$. The ply which has the minimum value of $\sigma_{B}^{i}$ is considered to fail at first. Once any one of the plies has failed, the effective modulus of the laminate is again calculated taking into account the elastic degradation of the failed ply. This procedure is repeated until all plies have failed. Numerical calculations were conducted on a carbon/glass hybrid FRP laminate subjected to uniaxial tension or compression. Calculated results were compared with experimental data obtained for carbon/glass hybrid FRP-FW pipes, and the availability of the proposed analysis was discussed.

(Received June 30, 1983)

\section{1. 緒武}

本研究は，ガラス緉維の延性，炭素䋐維の軽量性・高 剛性等, 強化繊維の特性を有効に利用したFRP 積層板 の開発之，その設計基準となる解析法を確立するととを 目的とする。筆者らは前報》で, 强化䋐維の異方性を考 虑に入れた一方向 FRPの弾性率解析法を提示した。本 報告では，その手法を基礎としてFRP 皘層板の平面応 力場に拉りる弾性率と强度の解析法を導く。

解析では，一方向FRPを任意の枚数貼り合わ甘たも デルを考え，以下の3つの仮定を拈いた。（1）マトリク

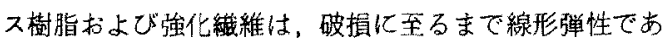

る。(2)皘層板厚さ方向の応力成分はゼロである(平面 応力場)。(3)積層板の厚さ方向之垂直な平面内0重は， すへての層について等しい。

また，積绝板各層の破損の判定にはTsai-Wuの2 次 破損条件式 ${ }^{2)}$ を用い，すへての層が破提するまでの枕力 一歪関係の計算法を定式化した。 CFRP/GFRPハイブ リッド皘層板が一軸引張り，または一軸王縮を受ける場 合の数値計算を行ない，FWパイプの実験結果と比較し た。 


\section{2. 弾性率解析}

\section{1 一方向 FRPの弹性率}

棈層板老構成する各層(一方向 FRP) の弹性率解析法 は前報りで詳述したので，ここでは必要な事項のみ簡羊 に記述する。一万向FRPは, 見加上上面内等方性(transversely isotropic)であり，弾性率の独立な成分は 5 個である。5 㑑の独乱成分を決定するために，試料に 加える外部応力 $\sigma_{i j}^{A}\llcorner し て 区 1 に$ 示した 5 通りの組合寸 在設定する。

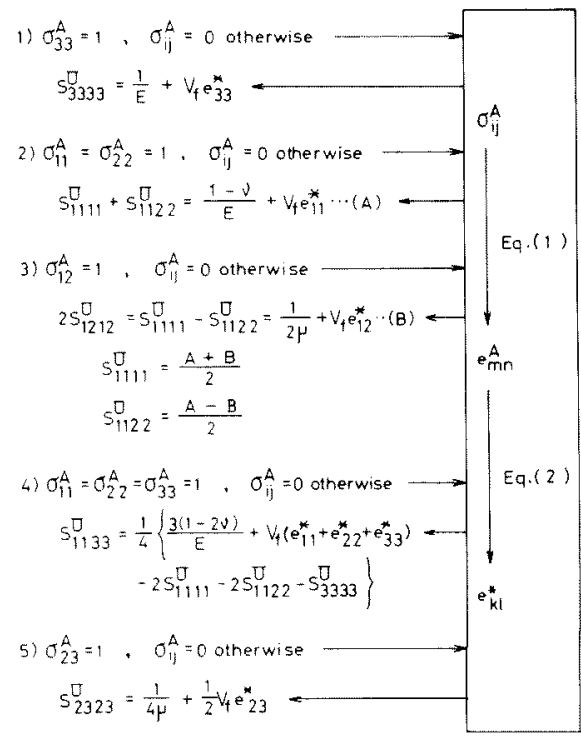

Fig. 1 Calculating procedure of the elastic com-

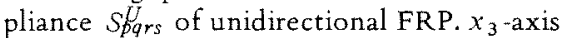
is taken along the fiber axis.

$$
\text { まず， } \sigma_{i j}^{A} \text { 加り } e_{m n}^{A} \text { 決定する。 }
$$$$
e_{m n}^{A}=S_{m n i j} \sigma_{i j}^{A}
$$

ここで $S_{m n i j}$ はトリクスの弾性コンプライアンスであ る。 $e_{m n}^{A}$ 在(2)式に代入して $e_{k l}^{*}$ を計算する。

$$
\begin{aligned}
& C_{p q m n}\left[e_{m n}^{A}+\left(1-V_{\mathrm{f}}\right)\left(T_{m n k l} e_{k l}^{*}-e_{m n}^{*}\right)\right] \\
& \quad=C_{p q m n}^{*}\left[e_{m n}^{A}+\left(1-V_{\mathrm{f}}\right) T_{m n k l} e_{k l}^{*}+V_{\mathrm{f}} e_{m n}^{*}\right]
\end{aligned}
$$

ここで, $C_{p q m n}, C_{p q m n}^{*}$ はマリクスおよび强化繊維の 弾性率， $T_{m n k l}$ はマトリクスのポアソン比によって決ま るEshelby のテンソル $V^{1}$ は繊維の体積分率である。

(2)式の解 $e_{k l}^{*}$ 在用いて，図1に示した様に，一力向 FRPの見加けの弾性コンプライアンス $S_{\text {pqrs }}^{U}$ を決定す る。因1でE，レ，仙，それぞれマトリクスのヤング 率, ポアソン比, 丼性率である。

\section{2 積曆板の弾性率}

本報告では，N層の一方向FRP 貼り合わ甘た棈層

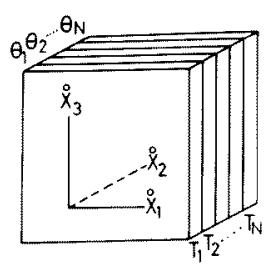

(a)

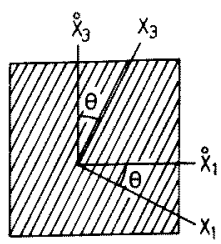

(b) $x_{2}=k_{2}$
Fig. 2 Coordinate system $\dot{x}_{n}(n=1,2,3)$ is fixed in the laminate (a), and the coordinate system $x_{m}(m=1,2,3)$ is taken along the principal axes of each ply (b). $\quad T_{i}, \quad \theta_{i} \quad(i=1 \sim N)$ denote the thickness and orientation angle of $i$-th ply, respectively. The coordinate system $x_{m}$ depends on the fiber orientation $\theta_{i}$.

板を考える。四2（a)で $\theta_{i} ， T_{i}(i=1 \sim N)$ はそれぞれi 層目の織維配向角と厚さ存表加す。各層の厚さ比 $t_{i}$ を (3) 式で定義する。

$$
t_{i}=\frac{T_{i}}{\sum_{j=1}^{N} T_{j}} \quad(i=1 \sim N)
$$

層によって繊維配向角 $\theta_{i}$ が異なるので，各層の主軸 万向座標系在 $\left(x_{1}, x_{2}, x_{3}\right)$ 亡し, 試料中に固定した座標

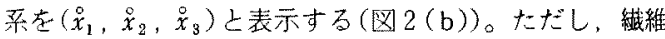

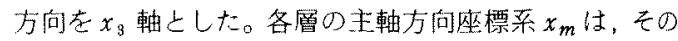
層の䄉維配向角 $\theta_{i}$ に依存する。 $x_{m}$ 座標と菂坐標との間 の方向余弦老 $a_{m n}$ とする。

$$
x_{m}=a_{m n} \stackrel{\circ}{x}_{n}
$$

図 2 (b) 場含，次式が成主つ。

$$
\left(\begin{array}{l}
x_{1} \\
x_{2} \\
x_{3}
\end{array}\right)=\left(\begin{array}{ccc}
\cos \theta & 0 & -\sin \theta \\
0 & 1 & 0 \\
\sin \theta & 0 & \cos \theta
\end{array}\right)\left(\begin{array}{l}
\dot{x}_{1} \\
\dot{x}_{2} \\
\dot{x}_{3}
\end{array}\right)
$$

前節の手法を各層 $(i=1 \sim N)$ 亿適用し，各層の主軸方 向座標采 $x_{m}$ における弾性コンプライアンス $S_{p q r s}^{i}=S_{p q r s}^{U}$ を求め，民れを方向余弦 $a_{m n}$ 索使って，試料中に固定し た座標系 $\dot{x}_{n}$ に変換する。

$$
\dot{S}_{k l m n}^{i}=a_{p k} a_{q l} a_{r m} a_{s n} S_{p q r s}^{i}
$$

各層の厚さ $\left(x_{2}=\dot{x}_{2}\right)$ 方向の応力成分をぜ口と仮定する 亡，i番目の層の忘力上歪の関係は次式で表わされる。

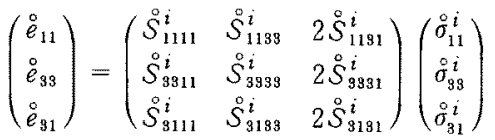

(7)式应力 $\sigma^{i}$ 亿ついて解き,

$$
\left(\begin{array}{l}
\sigma_{11}^{i} \\
\sigma_{33}^{i} \\
\sigma_{31}^{i}
\end{array}\right)=\left(\begin{array}{lll}
C_{11}^{i} & C_{13}^{i} & C_{15}^{i} \\
C_{31}^{i} & C_{33}^{i} & C_{35}^{i} \\
C_{51}^{i} & C_{53}^{i} & C_{55}^{i}
\end{array}\right)\left(\begin{array}{c}
\stackrel{o}{e}_{11} \\
\stackrel{e}{e}_{33} \\
\dot{o}_{31}
\end{array}\right)
$$

の形に整理する。（8）式は平面応力場でだり成り立つ関 
倸であり，平面蛋場または一般の 3 次元応力場では倸数 $C^{i}$ の值が異なる点に注意されたい。

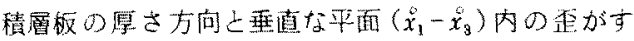
ぶての層について等しいと仮定すると，皘層板全体心応 力と歪の関保は次式で与无られる。

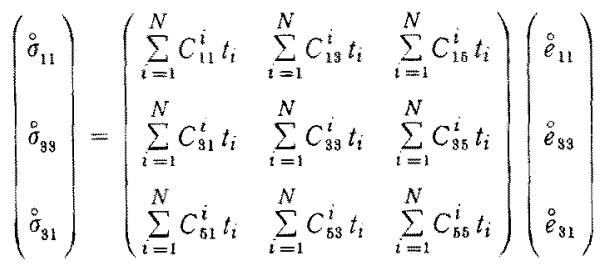

（9）式は，(8)式を使って各層の応力库均すること を意味する。 $t_{1}$ は(3) 式で定義した厚さ比でる。また

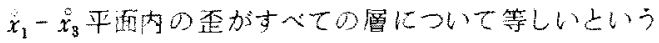

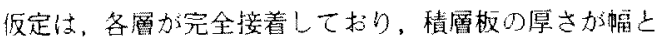
長さに比へて充分小さい場合省想定している。

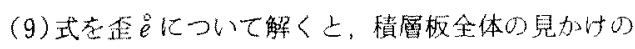
弾性コンプライアンス $S^{* *}$ 党得る。

$$
\left(\begin{array}{l}
\dot{e}_{11} \\
\dot{e}_{33} \\
\dot{e}_{31}
\end{array}\right)=\left(\begin{array}{lll}
S_{11}^{* *} & S_{13}^{* *} & S_{15}^{* *} \\
S_{31}^{* *} & S_{33}^{* *} & S_{35}^{* *} \\
S_{51}^{* *} & S_{53}^{* *} & S_{55}^{* *}
\end{array}\right)\left(\begin{array}{c}
\sigma_{11} \\
\sigma_{33} \\
\sigma_{31}
\end{array}\right)
$$

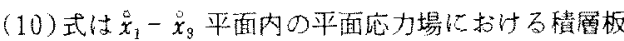

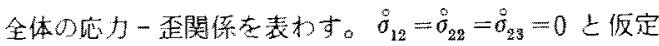

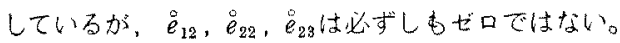

以上が皘層板の弾性率解析法である。

\section{3. 破断强度の予測}

\section{1 平面応力場における破損の判定}

图2(a)に示した $N$ 層加らなる啧層板に， $\check{x}_{1}-\check{x}_{3}$ 平面

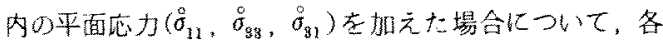
嶓の破損を判定する。

（1）まず前節で述べた手法により，瞔層板全体の見か けの弾性コンプライアンス $S^{* *}$ 老計算する。

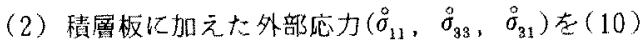

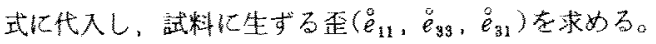
本郝告では， $\dot{x}_{1}-\check{x}_{3}$ 平面内で皘層板全体の歪亡各層の䄵 が等しい上仮定している。

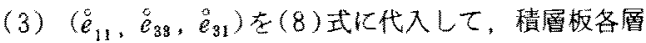
の応力 $\dot{\sigma}_{k l}^{i}(i=1 \sim N)$ 部算する。

（4）(4)式の方向余弦 $a_{m n}$ を使って，遂卓 $i$ 番目の

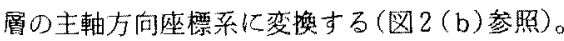

$$
\sigma_{m n}^{i}=a_{m k} a_{n} o_{k l}^{i}
$$

(5) $\sigma_{L}=\sigma_{33}^{i}, \sigma_{T}=\sigma_{11}^{i}, \tau_{L T}=\sigma_{31}^{i}$ t Tsai-Wu $\sigma$ 式,

（12）式，に代入して破損判定する。

$$
\begin{aligned}
\sigma_{L}\left(\frac{1}{X}\right. & \left.-\frac{1}{X^{\prime}}\right)+\sigma_{T}\left(\frac{1}{Y}-\frac{1}{Y^{\prime}}\right) \\
& +\frac{\sigma_{L}^{2}}{X X^{\prime}}-\frac{\sigma_{L} \sigma_{T}}{\sqrt{X X^{\prime} Y Y^{\prime}}}+\frac{\sigma_{T}^{2}}{Y Y^{\prime}}+\frac{\tau_{L T}^{2}}{S^{2}}=1
\end{aligned}
$$

Tsai \& $\operatorname{Hahn}^{37}$ は, $\sigma_{L} \sigma_{T}$ の係数を,

$$
2 F_{x y}=\frac{2 F_{x y}^{*}}{\sqrt{X X^{\prime} Y Y^{\prime}}}
$$

上置き，破損条件式力垂直応力成分心平西西閉曲線老表 わすためには，

$$
-1<F_{x y}^{*}<1
$$

でなければならないととを示している。また，等方性材

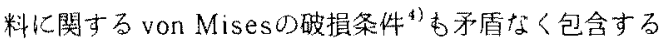
ためには，

$$
F_{x y}^{*}=-\frac{1}{2}
$$

上置けばよりと指摘している。そこで本報告では，F $F_{x y}^{*}$ $=-1 / 2$ 老採用した。

(12)式で， $X ， X^{\prime}$ は一方向FRPの瀻維 $(L)$ 万向の引 張拉よび瓜縮强度， $Y ， Y^{\prime}$ は横( $T$ )万向の引張および王 維强度，Sは主軸方向の剪断強度で势る。こ机らの定数 は程筧板各層化予如指定して求く。

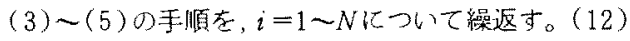
式左辺の值が 1 以上であれば，その層は鮍損すると判定 する。

\section{2 皘層板の一軸引張および生縮強度}

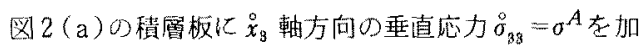
えた場合老考光る。

(1) 前節之同梾の手牘で，各層 $(i=1 \sim N)$ Kついて， $\sigma_{L}, \sigma_{T}, \tau_{L T}$ 去 $\sigma^{A}$ 関数として計算し，(12) 式に代入 する。(12)式和和関する2 次方程式であり，之の正

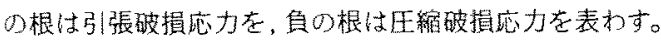

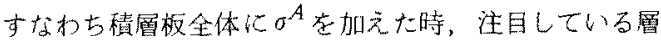
亿関する(12)式左边の值が 1 亿達すればその層は破損 する。以下の記述では簡単のため引張強度の計算法のみ 在記す。

（2） $N$ 買の破損応力(正の根)を此較し，その最小值を さがす。 $k$ 番目の層が最小でその傎が $\sigma_{\min }$ であるとする 上，本報告の計算では， $\sigma^{A} \leqq \sigma_{\min }$ の範国では，ヤング率 $E^{* *}=1 / S_{33}^{* *}$ の線形弾性であり， $\sigma^{A}=\sigma_{\min }$ で $k$ 番目の層 が最初化損する上予測する( $S_{93}^{* *} は(10)$ 式の值)。

（3）第 $k$ 層の破損以降は，之の層の積層板全体の剛性 儿刘する寄与加減少する。てれを厚さ此神の修正によ って考虑する。

$$
t_{k} \longrightarrow \beta_{k} t_{k} \quad\left(0 \leqq \beta_{k}<1\right)
$$

$\beta_{k}$ 少化定数 (coefficient of degradation) 々呼び， 
瀻維配向角等によって決まる各瓷（ $=1 \sim N)$ に固有の定数乞する。破損し た層の厚さ比を(13) 式で修正した拺 （9）式に代入して，雪ざ積層板全体の 弾性コンプライアンス $S^{* *}$ を計算し直 す。との $S^{* *}$ が, $\sigma^{A>\sigma_{\min }}$ における ヤング率老与える。

(4) 手順 (1) 人戻って同様の計算を, すべての䍰が破損するまで繰返す。た だし，手順(2)の比較ではすでに破椇 した層は除く。

(12) 式の正の根を $\sigma_{B}^{i}$ 表示して， 計算手順を図 3 に示した。压縮强度の 計算では，(12)式の負の根老 $\sigma_{B}^{i}$ 亡膡 き,その絶対值を比較すればよい。
Table 1. Elastic moduli of constituents.

\begin{tabular}{lccccc}
\hline & $\begin{array}{c}\text { Young's modulus } \\
\left(\mathrm{kg} / \mathrm{mm}^{2}\right)\end{array}$ & Poisson's ratio ${ }^{\text {a) }}$ & $\begin{array}{c}\text { Shear modulus } \\
\left(\mathrm{kg} / \mathrm{mm}^{2}\right)\end{array}$ \\
& $E_{1}$ & $E_{3}$ & $\nu_{12}$ & $\nu_{18}$ & $\mu_{23}$ \\
\hline Carbon fiber & 2100 & 23000 & 0.33 & 0.31 & 4200 \\
Glass fiber & 7400 & \multicolumn{2}{c}{0.22} & 3033 \\
Epoxy resin & 350 & 0.38 & 126.8 \\
\hline
\end{tabular}

a) Poisson's ratio $v_{12}$ indicates the strain ratio $-e_{11} / e_{22}$, when tensile stress $\left(\sigma_{22}\right)$ was applied in $x_{2}$-direction only.

Table 2. Layer structure of CFRP/GFRP hybrid laminate.

\begin{tabular}{cccccc}
\hline Layer No. & C or G & $V_{f}$ & $\theta\left(^{\circ}\right)$ & $t_{i}$ & $\beta_{i}$ \\
\hline 1 & CFRP & 0.701 & +49 & 0.182 & 0.8 \\
2 & CFRP & 0.701 & -49 & 0.182 & 0.8 \\
3 & GFRP & 0.452 & 90 & 0.271 & 0.8 \\
4 & GFRP & 0.452 & +24 & 0.1825 & 0 \\
5 & GFRP & 0.452 & -24 & 0.1825 & 0 \\
\hline
\end{tabular}

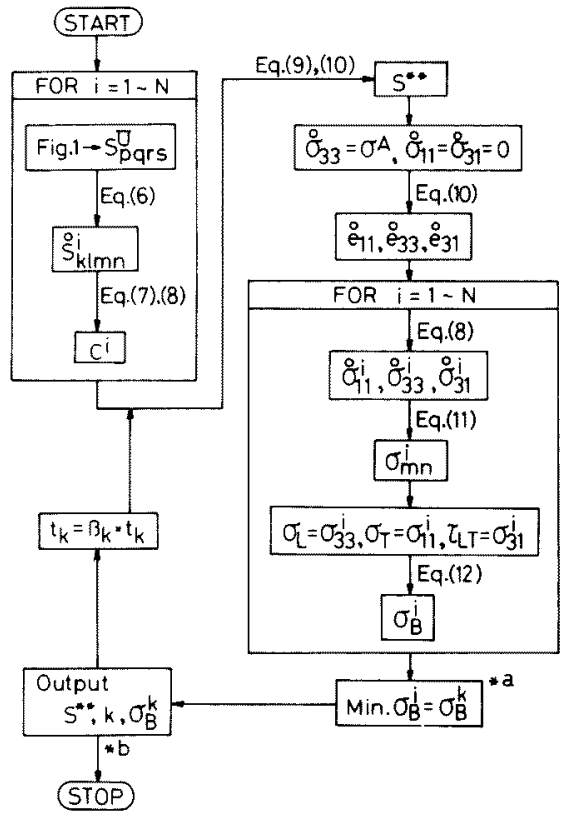

Fig. 3 Calculating procedure of elastic compliance of the laminate; $S^{* *}$, and the tensile stress $\sigma_{B}^{k}$ at which $k$-th ply fails. Uniaxial tensile stress $\sigma^{A}$ is applied to $\dot{x}_{3}$-direction in Fig. 2. When $k$-th ply has failed, the thickness ratio $t_{k}$ is multiplied by the degradation coefficient $\beta_{k}\left(0 \leqq \beta_{k}<1\right)$. And the calculation of $S^{* *}$ and $\sigma_{B}^{k}$ is repeated until all plies have failed.

*a In comparing $\sigma_{B}^{i}$, the plies which have already failed are excluded.

*b When all plies have failed, the calculation is closed.
Table 3. Parameters for failure criterion.

\begin{tabular}{rrrrrr} 
& & & \multicolumn{2}{c}{$\left(\mathrm{kg} / \mathrm{mm}^{2}\right)$} \\
\hline CFRP & $X$ & $X^{\prime}$ & $Y$ & $Y^{\prime}$ & $S$ \\
GFRP & 130 & 70 & 5 & 10 & 8 \\
\hline
\end{tabular}

\section{4. 数值計算例}

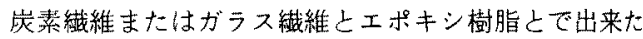
一方向FRPを構成要素しする，CFRP/GFRPハイブ リッド皘層板に関する数值計算例を示す。計算に用いた 素材心弾性率表 1 亿示す。

積層板の層構成は，筆者らが行なったFRP-FWパイ

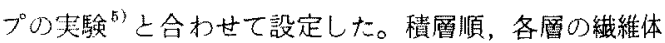
皘尔率，織維配向角，厚さ比书よざ劣化定数 $\beta_{i}$ を表2

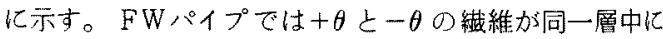
淈在しているが、計算では別々の層と考えた。(12)式 の破損判定に用いる定数を表 3 に示す。これは，一方向 FRP に関する基礎実験 ${ }^{6)}$ から决定した值である。

表 4 に一軸引張および死縮の計算結果を示す。引張で は，初期ヤング率が $1964 \mathrm{~kg} / \mathrm{mm}^{2}$ ，ポアソン比が 0.472 で.引張応力 $9.7 \mathrm{~kg} / \mathrm{mm}^{2}$ でフープ(GFRP 90) 層が最䘞 に破損する。次に，ヤング率が $1884 \mathrm{~kg} / \mathrm{mm}^{2}$ に低下し， 引張応力 $13.4 \mathrm{~kg} / \mathrm{mm}^{2}$ で CFRP $+49^{\circ}$ 層と $-49^{\circ}$ 層加同 時に皮損する。その捘ヤング率が $1745 \mathrm{~kg} / \mathrm{mm}^{2}$ K低下 し, 最終的に応力 $32.8 \mathrm{~kg} / \mathrm{mm}^{2}$ で GFRP $\pm 24^{\circ}$ 層が破 断する。

この応力ー需曲線を四 4 亿害線で示した。罒5 は王縮 応力ー专曲線である。図中の破線はC/GFRP-FWパイ プに関する実験結果 ${ }^{5)}$ である。実験值は計算值より大き な延性を示しているが, 䨤1\%程度までは引張, 王縮と 
Table 4. Calculated results of tensile and compressive properties of CFRP/GFRP hybrid FW pipes.

\begin{tabular}{lccrr}
\hline \multirow{3}{*}{ Tension } & $\begin{array}{c}\text { Young's } \\
\text { modulus } \\
\left(\mathrm{kg} / \mathrm{mm}^{2}\right)\end{array}$ & $\begin{array}{c}\text { Poisson's } \\
\text { ratio }\end{array}$ & $\begin{array}{r}\text { Failed } \\
\text { layer }\end{array}$ & $\begin{array}{r}\text { Failure } \\
\text { stress } \\
\left(\mathrm{kg} / \mathrm{mm}^{2}\right)\end{array}$ \\
\hline \multirow{3}{*}{ Compression } & 1964 & 0.472 & $\mathrm{G} 90^{\circ}$ & 9.7 \\
& 1884 & 0.495 & $\mathrm{C} \pm 49^{\circ}$ & 13.4 \\
& 1745 & 0.476 & $\mathrm{G} \pm 24^{\circ}$ & 32.8 \\
\hline & 1964 & 0.472 & $\mathrm{C} \pm 49^{\circ}$ & -17.4 \\
& 1822 & 0.451 & $\mathrm{G} 90^{\circ}$ & -20.1 \\
& 1745 & 0.476 & $\mathrm{G} \pm 24^{\circ}$ & -25.4 \\
\hline
\end{tabular}

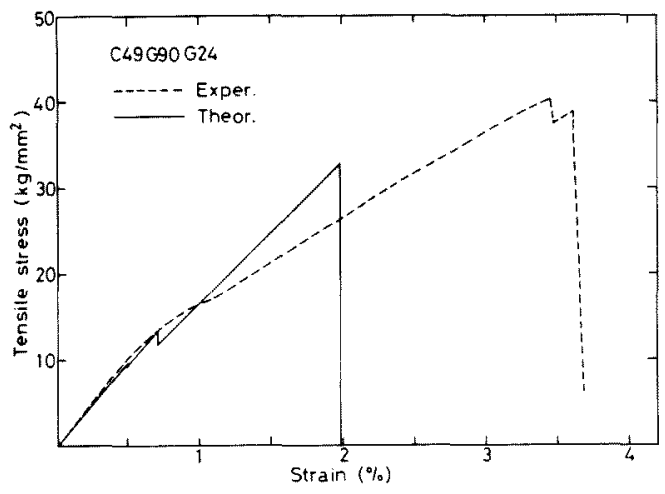

Fig. 4 Tensile stress-strain relation of C/G hybrid FRP-FW pipes. Specification of the specimen is shown in Table 2 , and numerical values calculated are given in Table 4 .

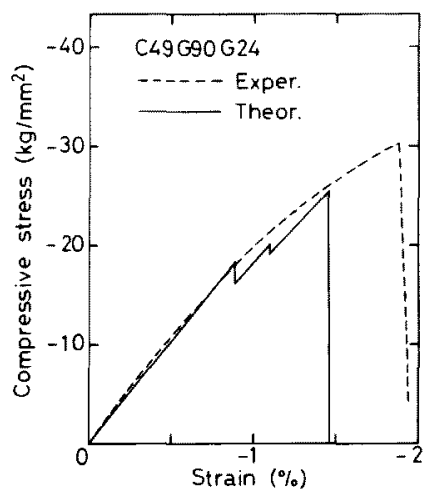

Fig. 5 Compressive stress-strain relation of $\mathrm{C} / \mathrm{G}$ hybrid FRP-FW pipes. Calculated diagram $(-)$ is relatively in good agreement with experimental result (-----), except for large elongation observed in experiment.
屯，実験値之計算値之の間に良い一致肪得ら れた。

\section{5. 結言}

FRP䄸層板の弹性事乞強度を予测するた めの数值計算法を提示した。弾性率の解析で は，一方向FRPを $N$ 枚貼り合わせたモデル 考若，厚さ力向の芯力成分はゼ口上仮定し た。また，各層は完全接着しており，厚さ力 向之垂直な平面内に招りる歪はすへてての層に ついて等しい上仮定した。棈層板各層の破損 の判定には Tsai-Wuの2 次破損条件式 ${ }^{2)}$ 用いた。ある層が破損すると，棈蟹板全体の剛性に対す るその層の寄与は低下する。この影響を、破損した層の 厚さ比の修正によって考営し，すべての層が破損するま での応力ー丕関係を計算する手順を導出した。

$\mathrm{C} / \mathrm{G}$ ハイブリッド FRP積層板が一軸引張または圧縮 在受ける場合の数值計算を行ない，FRP-FWパィプの 実験結果上比較した。実験で観測される大きな延性は予

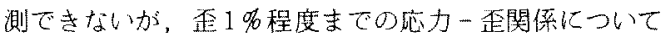
ははば良い一致が得られた。

本報告の実験之は別に行なった，一方向FRPの剪断 强度(S)を測定する基礎実験(フープ巻だけのFWパイ

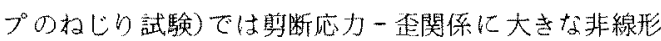
性が表われ ${ }^{6)}$ ，また織維巻角度士 $30 \sim 60^{\circ}$ のWパイプの

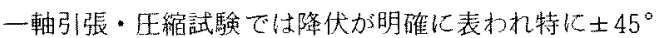
付近心試料は著しく大きな延性を示す結果を得た ${ }^{7,8)}$ 。

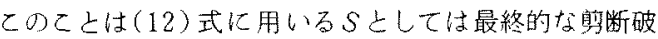
壊応力上りも降伏応力のほうが滴切であることを示唆し ている。また一軸引張・王縮によって大きな剪断応力 $\tau_{L T}$ 老生ずる瀻維配向角 $30 \sim 60^{\circ}$ の層に対しては，降伏 珑剛性の低下に応じて劣化定数 $\beta_{k}$ 老設定する必要があ る。すな打ち， $\beta_{k}$ 在一定值记固定女ず䄳の関数として， 歪の增加上共に $\beta_{k}$ 小さくしていく段階的繰返し計算 を行なえば計算の精度をより高的ることが可能と考元ら れる。四 4,5 に示した数値計算では，CFRP $\pm 49^{\circ}$ 層の $\beta_{k}$ を单純に 0.8 上おいたため歪 $1 \%$ 程度までしか計算值 上実験值に良好な一致が得ら扎ず，加実験結果に表水 れる大きな延性も予測できなかった。

な找筆者らが先に行なった霓験”から，GFRP $24^{\circ}$ 層 は结線形弾性を示し脆性破断すると予测されるため， $\beta_{k}=0$ 之扔いた。一方向 FRPO横 $\left(90^{\circ}\right)$ 方向引張・王 縮强度 $\left(Y, Y^{\prime}\right)$ の測定では，破断に至るまでほぼ線形弾

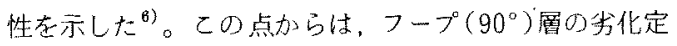
数を $\beta_{k}=0$ とおくできであるが， $\beta_{k}=0$ よりも0.8とお いた計算値の方が実験值と良い一致を示した。その原因 
として、フープ層は，FWパイプの長さ方向に破損した 後も，用周方向心変形を拘束する効果を保持するととが 考えられる。

また本報告の解析法は，䦩間応力が無視できない場合 や，自由端を持つ皘層平板で自由端近傍の応力特異性が 破損に重要な影響を及ばす場合には適用できない。しか し，以下に述べる2つの理由から $\mathrm{FW}$ パイプに対しては 適用性があると考元ら机る。

（1）プリプレグシートを皘層する場合上比へて，フィ ラメントワインディング $(\mathrm{FW})$ 法で成形した試料は層之 層との境界が入り組んでおり，層間鼏断破壊の危険性が 少ない。

（2）パイプ形状であるため自由端が存在しない。 次の趣告では，本報告の解析法を種々のFRP-FWパ イプに応用し,一方向FRP 破損判定基染 $\left(X, X^{\prime}, Y\right.$, $\left.Y^{\prime}, S\right)$ および尔化定数 $\beta_{k}$ の設定について検討する。 付記: 本研究は昭和 57,58 年度文部省科学研究費 (総 合研究(A) 課題番号57390012)の補助を受けた。

\section{参考文献}

1）高橋清久，原川和久，伴菊夫，酒井哲也; 纎学誌, 39, 349 (1983)

2) S. W. Tsai and E. M. Wu; J. Composite Materials, 5, 58 (1971)

3) S. W. Tsai and H. T. Hahn; "Introduction to Composite Materials", Technomic Pub. Co., Westport, Connecticut, p. 277 (1980)

4) R. von Mises; Zeits. ang. Math. Mech.. 8, 161 (1928)

5) K. Ban, K. Takahashi and T. Sakai; "Progress in Science and Engineering of Composites" (ed. by T. Hayashi, K. Kawata and S. Umekawa), JSCM, p. 1153 (1982)

6) 高橋清久，伴 菊夫；投稿準備中

7) 伴菊夫，大塚裕光，高橋清久; 瀻学誌， $37 ４ 20$ (1981)

8) 高橋清久，伴菊夫，酒井哲也；繊維学会，昭和 58 年度年次大会研究発表会講淇要旨集, p.238(1983) 